\title{
A Decision-Making Model of Technological-Focused Government Agency Selection of Technological Start-Up Businesses
}

\author{
Amnard Taweesangrungroj ${ }^{*}$, Roongkiat Rattanabanchuen and \\ Sukree Sinthupinyo \\ Program of Technopreneurship and Innovation Management, Chulalongkorn University, \\ Pathumwan, Bangkok 10330, Thailand
}

("Corresponding author's e-mail: amnard_t@ @hotmail.com)

Received: 7 March 2021, Revised: 23 June 2021, Accepted: 7 July 2021

\begin{abstract}
In developing countries, the government has played an important role in supporting startup businesses in various aspects, primarily through tech-focused government agencies. With a limited budget, the government agencies are critical to select plenty of tech startups for funding, leaving only promising tech startups. Consequently, government agencies inevitably face decision-making problems under uncertain circumstances, like private equity investment situations. Reviewing the relevant decisionmaking frameworks has identified that a classical multiple criteria decision-making (MCDM) approach is currently used, assuming decision-makers acquire complete information that is not realistic. Moreover, both qualitative and quantitative criteria used in evaluating startup businesses cannot represent the uncertainty which is the fundamental nature of the decision-making circumstance. Thus, this article presents a decision-making framework of tech-focused government agencies for selecting startup businesses based on a fuzzy MCDM of Technique for Order Preference by Similarity to Ideal Solution (TOPSIS). Besides, it identifies selection criteria with mixed research methodologies and determines weights of importance criteria by the Delphi method. Finally, the proposed framework results are fairness, transparency, and eliminating bias in decision-making, including more efficiency when the framework's ranking orders significantly correspond with actual performances.
\end{abstract}

Keywords: Decision-making, Government agency, Startup business, Selection process, Fuzzy TOPSIS

\section{Introduction}

As transforming to Thailand 4.0 era, Thailand has confronted a challenge with the middle-income trap, inequality trap, and imbalanced trap in society and economy. Consequently, the Thai government had created Thailand 4.0 policy for using technology and innovation as a useful tool to drive the economy. Besides, they are essential to creating value-added to local products and services for competing in international trading. Responding to the policy, the government continuously supports various industries such as FinTech, AgTech, HealthTech, and others [1] for transforming to Thailand 4.0 era successfully.

Since the policy establishment in 2016, the Thai government has continuously supported tech startups to increase new high technology businesses. Because they usually use technology or innovation as a tool to convert business ideas into products or services [2] that are consistent with the policy's objectives. In 2017, the Thai Ministry of Industry reported an increase of 8,000 startups from a few years ago, which previously were only 100 to 200 firms; however, $80 \%$ of them were in the idea and seed stages. In 2019, venture capital investments markedly increased at 97.55 million USD from 32 deals than investments in 2018 (61.25 million USD from 36 deals) [3]. Decreasing deals indicated that private equity investors (venture capitalists, corporate venture capitalists, and angel investors) were cautiously investing in startup businesses. Investors tend to invest in high-quality tech startups expected to provide a high return of investment in the future. Consequently, private equity investments are the similarity in Thailand and the USA [4].

Although the financial resources of private equity investors currently play an important role in creating and nurturing startup businesses, only $1-2 \%$ of startups can successfully attract these investors to invest in their business [5]. As the above results, plenty of startups still lack the funds to support their 
businesses. To solve the problem, government agencies have provided supports to those startups such as funding [6,7], knowledge, collaboration with universities, tax benefits, or consulting [6-9]. Therefore, fundraising from tech-focused government agencies becomes popular among tech startups who fail to fundraise private equity investors. Tech-focused government agencies do not aim to gain any return from their backed startups, but they expect that backed startups contribute to developing and driving the economy forward $[6,7]$.

Even though the Thai government currently allocates numerous budgets to support tech startups through tech-focused government agencies, the budgets are insufficient to support entire tech startups. Therefore, tech-focused government agencies are required to thoughtfully select tech startups who apply for getting supports to obtain only promising tech startups for their funds. This necessity has pushed the government agencies to face a challenge in decision-making under uncertain circumstances that could lead to erroneous decisions [10]. Addressing issues, a set of criteria, and a framework in the government agency's decision-making can solve vagueness, subjectivity, and uncertainty in selecting startup businesses $[6,7,12,13]$. Moreover, a fair and transparent selection process is also presented in this article.

The $1^{\text {st }}$ section identifies the decision criteria used in this article by reviewing relevant literature and conducting mixed research methodologies to identify a group of decision criteria appropriate to techfocused government agencies' selection process. Next, definitions and formulas of the fuzzy TOPSIS approach are introduced, and it can effectively select high potential tech startups for government supports. Finally, a numerical example is expressed of how the fuzzy TOPSIS approach ranks and selects promising tech startups to ensure that the proposed framework can work as the expectations.

\section{Literature review}

Studying the decision-making process for selecting startup businesses is not only conducive for private equity investors or government agencies to make better decisions, but it can create an opportunity for startups to gain the desired capital for creating their business dream to reality. However, selecting an appropriate decision-making approach is the most critical problem for private equity investors in their decision-making process. In this article, we searched an appropriate approach in the context of techfocused government agencies' decision-making by studying venture capitalists' decision-making approaches such as AHP (Analytical hierarchy process) [11], MAVT (Multi-attribute value theory) [12], Fuzzy AHP [15,16], Fuzzy goal programming (GP) [13], Fuzzy PROMTHEE I and II (Fuzzy Preference Ranking Organization Method for Enrichment Evaluation) [4,7], IFPT (Intuitionistic fuzzy technique for order preference by similarity to ideal solution) [6,16] which have been studied for selecting promising startup businesses. These approaches can be applied in the context of the tech-focused government agency's decision-making because the government agencies' decision-making process bases on the venture capitalists' decision-making process [14-16].

\section{Success factors of startup businesses}

Most entrepreneurs focus on business success and the factors that lead to success are crucial. When entrepreneurs well understand success factors, they will have a guideline for leading their businesses quickly as well as avoid pitfalls or failures in business effectively. In 1987, Macmillan et al. researched 150 companies which consisted of both successful and unsuccessful startup companies, and revealed that the business success was related to revenue, market share, return of investment, and low costs [17] and profits [17,18]. Another research by Stuart and Abetti presented success factors of high technology ventures which included market size, business model innovation, networking, team, R\&D teams, experiences in technology and business, customer acceptance, and organization management [18]. Besides, the entrepreneur's quality, resource allocation, and marketing strategy considerably were part of the success factors of startup businesses [19]. Subsequently, Chorev and Anderson studied the successes and failures of emerging high technology ventures and found that high technology ventures could succeed in their businesses with the business idea, strategies, teams, management, customer relationship, and research and development. Furthermore, there were external factors that could support the business to success such as the economy, government policies, and business environment [20]. However, venture capitalists who usually work with many startups mentioned that the success factors of startup businesses were business model innovation, business collaborations, and focusing on strong businesses. Besides, they also mentioned that most failed startup businesses were backed by inappropriate venture capitalists who lacked knowledge and particularly looked for short-term investments [21].

In Thailand, some works indicted that success factors were mentioned to business model innovation, networks and collaborations, the creation of new demands, teams, the government supports, the attitude of entrepreneur, and speed for pushing products and services to the market. Whilst, the failures of startup 
businesses were caused by insufficient knowledge, high competition, and short-term business operation [22]. Meanwhile, some works studied the success factors of startups in Thailand and their results revealed that the main success factors of startup businesses consisted of timing, teams, business idea, business plan, and capital [23].

\section{Government supports startup businesses}

Small and Medium Enterprises (SME) is a significant economic driver in terms of generating incomes and employment in the country, while the startup is also a type of SME with the same business size, and they similarly play roles as SME does [4,27,28]. Generally, several countries recognized this importance; therefore, they had fully provided supports to tech startups to ensure that they could survive in industrial competition. In some countries, the most government supports were focused on developing products with higher technology, such as supports for research and development (R\&D) by the public research and development funding [8,9] or supports in pushing products to commercialization and exploiting $R \& D$ centers of universities and research centers $[8,10]$.

In some developing countries, the government had established the government venture capital (GVC) to support funds to startup businesses because financial resources by private equity investors were insufficient. For this reason, numerous tech startups could not gain their desired capital for running their businesses. Therefore, the government financial resource was crucial for developing startup businesses $[6,7,10]$. In Thailand, the government pays attention to the national economic development to surpass the middle-income trap by initiating the Thailand 4.0 policy to encourage the private sectors to develop their products and services using innovation and technology [1,2]. From the implementation of this strategy, the number of tech startups had increased as the objective of the strategy, and the funds provided by tech government agencies could accelerate backed tech startups in launching their products and services to market successfully $[3,8,10,11]$.

\section{Criteria for selecting startup businesses}

Several authors researched the criteria used by investors such as venture capitalists and angel investors to select startup businesses but had 1 specific research on the decision process for selecting startup businesses by the tech-focused government agency. In Table 1, some relevant works of criteria in selecting startup businesses from various literature complied. The criteria could categorize as entrepreneur' characteristics, product characteristics, market characteristics, financial considerations, management skills, economic environment, and institutional and regulatory environment. Generally, some criteria were considered qualitative criteria such as leadership capability, competitive advantage, or product uniqueness. In contrast, some criteria could be identified as crisp numbers and considered quantitative criteria such as market share, the return of investment, or the payback period. In a situation of pitching, decision-makers would acquire both qualitative and quantitative information during presenting businesses. For traditional decision-making, quantitative criteria were specific and evaluated rapidly, while decision-makers could not instantly evaluate qualitative criteria because of the uncertainty of information was obtained. Resolving the issue, the fuzzy set theory can be applied in the selection process and can effectively use with both qualitative and quantitative criteria. The next section presents the fuzzy set theory and the fuzzy TOPSIS approach, respectively.

\section{The multiple criteria decision-making used by venture capitalists}

The decision-making of venture capitalists for selecting startup businesses was based on MCDM approaches categorized as conventional MCDM approaches and fuzzy MCDM approaches. Typically, conventional approaches were applied to certain information and could be evaluated by crisp numbers. In comparison, the fuzzy set theory in fuzzy MCDM approaches was used to address uncertainty vagueness, subjectivity, and imprecision. Additionally, the fuzzy set theory could be effectively applied to qualitative and quantitative information $[6,7,11]$.

In conventional MCDM approaches, there was an effort to implement the actuarial model in venture capitalists' decision-making process. When the information in decision-making was increased, decisionmakers must spend plenty of time interpreting the new information. Moreover, bias occurred by new information incorrectly guided decision-makers to believe that the interested businesses were profitable. The actuarial model addressed the above issue, and it could reduce the bias influenced to judgments of decision-makers and increase the accuracy of decision-making [24].

Meanwhile, AHP was applied in selecting new ventures, and selected new ventures were expected to gain a high return of investment in the future. AHP used a pairwise comparison method in the selection process and provided a well-structured selection process to investors seeking promising ventures [11]. 
Next, the MAVT was introduced to support VCs in selecting promising ventures. The MAVT approach created a systematic structure that could reduce bias and increased transparency in the selection process [12]. However, the approaches mentioned earlier had not yet been supported to apply with qualitative factors.

Afterward, researchers initially realized the effects of the qualitative factor that influenced private equity investors' decision-making. The fuzzy MCDM approaches were applied to the decision-making process to increase accuracy and efficiency, such as introducing the fuzzy AHP to support investors interested in investing in venture capital companies with good performance [25]. This approach was also used to prioritize risks in VCs' decision-making for mitigating risks that occurred in investment and increase the return of investment at high levels [26].

A most used technique, fuzzy PROMETHEE, has introduced a GVC decision-making model based on fuzzy PROMETHEE to select high potential startup businesses worth the investment [27]. Next, Yang and Zhao adopted the decision-making model based on modified PROMETHEE II to select promising SMEs for venture capital investment. It was found that startups in the USA had entered the bubble stage that impacted venture capitalists to invest in startups more carefully. Therefore, the selection process for startup businesses must be increased more efficiently using the mentioned MCDM approach to acquire high potential businesses for long-term investment [4].

With the increasing popularity of a fuzzy MCDM approach, the intuitionistic fuzzy technique for order preference by similarity to ideal solution (IFPT) was introduced in the decision-making of public venture capital. The proposed decision-making framework reduced bias in decision-making and built transparency in the selection process by engaging decision-makers to determine weights of importance criteria with an intuitionistic fuzzy technique [28]. Afterward, Tian et al. conducted the IFPT approach to apply in the VC decision-making for select promising startup businesses. As the result of the proposed framework, it indicated that the selection process of VC's decision-making was increased more efficiency for selecting promising startups [29].

To introduce other MCDM approaches, Aouni et al. used fuzzy GP to select proper ventures for their investment. These ventures should have successfully raised antecedent funds from other VCs or were in at least the stage of series A [13]. However, past research mostly focused on studying the decision-making of either private or public equity investors. The past works indicated that the introduced decision-making framework tended to be applied with tech-focused government agencies for selecting startup businesses. Consequently, this study proposes a decision-making framework to support the government agency's decision-making under uncertain circumstances to improve their decision-making more efficiently for deriving potential startup businesses worthy of government support. 
Table 1 Criteria for selecting startup businesses in private equity investors.

\begin{tabular}{|c|c|c|c|c|c|c|c|c|c|c|c|c|c|c|c|c|c|c|c|}
\hline Criteria & Sub-criteria & 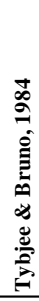 & 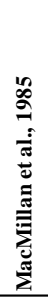 & 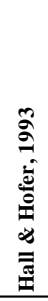 & 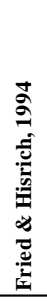 & 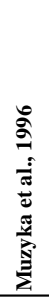 & 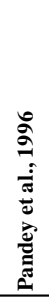 & 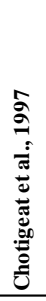 & 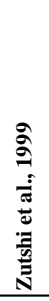 & 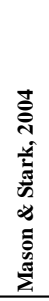 & 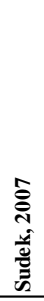 & 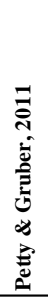 & 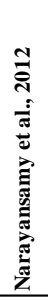 & 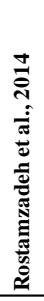 & 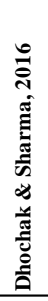 & 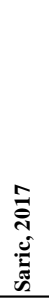 & 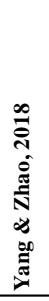 & 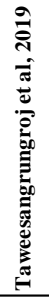 & Total \\
\hline \multirow[t]{11}{*}{ Entrepreneur's characteristics } & Track record & & $\checkmark$ & & & $\checkmark$ & $\checkmark$ & $\checkmark$ & $\checkmark$ & $\checkmark$ & $\checkmark$ & $\checkmark$ & & $\checkmark$ & $\checkmark$ & $\checkmark$ & $\checkmark$ & & 12 \\
\hline & Leadership capability & & $\checkmark$ & & $\checkmark$ & $\checkmark$ & $\checkmark$ & $\checkmark$ & $\checkmark$ & & & $\checkmark$ & $\checkmark$ & $\checkmark$ & $\checkmark$ & $\checkmark$ & $\checkmark$ & $\checkmark$ & 13 \\
\hline & Commitment & & $\checkmark$ & $\checkmark$ & $\checkmark$ & & $\checkmark$ & $\checkmark$ & $\checkmark$ & & $\checkmark$ & $\checkmark$ & $\checkmark$ & $\checkmark$ & & $\checkmark$ & & & 11 \\
\hline & Risk evaluation & & $\checkmark$ & $\checkmark$ & $\checkmark$ & & $\checkmark$ & $\checkmark$ & $\checkmark$ & & & & $\checkmark$ & $\checkmark$ & $\checkmark$ & $\checkmark$ & $\checkmark$ & & 11 \\
\hline & Skills and experience & & & $\checkmark$ & $\checkmark$ & & $\checkmark$ & $\checkmark$ & & $\checkmark$ & & $\checkmark$ & $\checkmark$ & & $\checkmark$ & $\checkmark$ & $\checkmark$ & & 10 \\
\hline & Market familiarity & & $\checkmark$ & & $\checkmark$ & $\checkmark$ & $\checkmark$ & $\checkmark$ & & & $\checkmark$ & & $\checkmark$ & $\checkmark$ & & $\checkmark$ & $\checkmark$ & & 10 \\
\hline & Business idea & & $\checkmark$ & $\checkmark$ & $\checkmark$ & & & & $\checkmark$ & $\checkmark$ & & & $\checkmark$ & $\checkmark$ & & $\checkmark$ & & & 8 \\
\hline & Reliability & & $\checkmark$ & & & & $\checkmark$ & $\checkmark$ & & & $\checkmark$ & & & $\checkmark$ & & $\checkmark$ & & $\checkmark$ & 7 \\
\hline & Honesty and integrity & & & & $\checkmark$ & & $\checkmark$ & $\checkmark$ & & & & & $\checkmark$ & & $\checkmark$ & & & & 5 \\
\hline & Attention to details & & $\checkmark$ & & & & & & $\checkmark$ & & & & & & & $\checkmark$ & & $\checkmark$ & 4 \\
\hline & Compatibility with investor & & $\checkmark$ & & & & & & & & & & & & & $\checkmark$ & $\checkmark$ & & 3 \\
\hline \multirow[t]{8}{*}{ Products and services } & Patentability & $\checkmark$ & $\checkmark$ & $\checkmark$ & & & & & $\checkmark$ & & $\checkmark$ & $\checkmark$ & & $\checkmark$ & $\checkmark$ & $\checkmark$ & $\checkmark$ & & 10 \\
\hline & Product uniqueness & $\checkmark$ & & $\checkmark$ & & $\checkmark$ & $\checkmark$ & $\checkmark$ & & $\checkmark$ & & $\checkmark$ & & $\checkmark$ & & & $\checkmark$ & $\checkmark$ & 10 \\
\hline & High technology & $\checkmark$ & $\checkmark$ & $\checkmark$ & & & $\checkmark$ & $\checkmark$ & & $\checkmark$ & & $\checkmark$ & & $\checkmark$ & & $\checkmark$ & & & 9 \\
\hline & Product acceptability & & $\checkmark$ & & & & $\checkmark$ & $\checkmark$ & $\checkmark$ & & & $\checkmark$ & & & $\checkmark$ & $\checkmark$ & & & 7 \\
\hline & No imitative product & $\checkmark$ & & & & & $\checkmark$ & $\checkmark$ & & & & $\checkmark$ & & $\checkmark$ & & & $\checkmark$ & & 6 \\
\hline & Functioning prototype & & $\checkmark$ & & & & $\checkmark$ & $\checkmark$ & $\checkmark$ & & & & & & & $\checkmark$ & & $\checkmark$ & 6 \\
\hline & Selling potential & $\checkmark$ & & & & & & & & & & $\checkmark$ & & $\checkmark$ & $\checkmark$ & & & & 4 \\
\hline & Resistance to economic cycle & & & & & $\checkmark$ & $\checkmark$ & $\checkmark$ & & & & & & & & & & & 3 \\
\hline \multirow[t]{11}{*}{ Market characteristics } & Market growth & $\checkmark$ & $\checkmark$ & & $\checkmark$ & $\checkmark$ & $\checkmark$ & $\checkmark$ & $\checkmark$ & $\checkmark$ & $\checkmark$ & $\checkmark$ & $\checkmark$ & $\checkmark$ & $\checkmark$ & $\checkmark$ & $\checkmark$ & $\checkmark$ & 16 \\
\hline & Market size & $\checkmark$ & & $\checkmark$ & & $\checkmark$ & $\checkmark$ & $\checkmark$ & & $\checkmark$ & $\checkmark$ & $\checkmark$ & & $\checkmark$ & $\checkmark$ & & $\checkmark$ & $\checkmark$ & 12 \\
\hline & Competitive advantage & & & & $\checkmark$ & $\checkmark$ & & & $\checkmark$ & & $\checkmark$ & $\checkmark$ & $\checkmark$ & $\checkmark$ & $\checkmark$ & & $\checkmark$ & $\checkmark$ & 10 \\
\hline & Little threat of competition & $\checkmark$ & $\checkmark$ & $\checkmark$ & & & $\checkmark$ & $\checkmark$ & & & & & & & $\checkmark$ & $\checkmark$ & $\checkmark$ & & 8 \\
\hline & Familiar with industry & & $\checkmark$ & $\checkmark$ & & & & & & $\checkmark$ & & & & & & $\checkmark$ & $\checkmark$ & & 5 \\
\hline & Market stimulation & $\checkmark$ & $\checkmark$ & & & & & & & & & & & & $\checkmark$ & $\checkmark$ & & & 4 \\
\hline & New market creation & & $\checkmark$ & & & & $\checkmark$ & $\checkmark$ & & & & & & & & $\checkmark$ & & & 4 \\
\hline & Create post entry barrier & & & & & $\checkmark$ & & & $\checkmark$ & & $\checkmark$ & & & & & & $\checkmark$ & & 4 \\
\hline & Market risk & & & $\checkmark$ & & & & & & & & & & $\checkmark$ & & & $\checkmark$ & & 3 \\
\hline & Distribution channel & $\checkmark$ & & & & $\checkmark$ & & & & & & & & $\checkmark$ & & & & & 3 \\
\hline & Cost of initial market testing & & & & & & & & & & $\checkmark$ & & & $\checkmark$ & & & & & 2 \\
\hline \multirow[t]{8}{*}{ Financial consideration } & High return of investment & & $\checkmark$ & $\checkmark$ & $\checkmark$ & $\checkmark$ & $\checkmark$ & $\checkmark$ & $\checkmark$ & $\checkmark$ & $\checkmark$ & $\checkmark$ & $\checkmark$ & $\checkmark$ & $\checkmark$ & $\checkmark$ & $\checkmark$ & & 15 \\
\hline & Profitability and liquidity & & $\checkmark$ & $\checkmark$ & & $\checkmark$ & $\checkmark$ & $\checkmark$ & $\checkmark$ & & $\checkmark$ & & & $\checkmark$ & $\checkmark$ & $\checkmark$ & & & 10 \\
\hline & Exit strategy & & & & $\checkmark$ & & $\checkmark$ & $\checkmark$ & & & $\checkmark$ & $\checkmark$ & $\checkmark$ & $\checkmark$ & & & & & 7 \\
\hline & Size of investment & & & $\checkmark$ & $\checkmark$ & & & & & $\checkmark$ & $\checkmark$ & & $\checkmark$ & $\checkmark$ & & & & & 6 \\
\hline & Payback period & & & & & $\checkmark$ & & & & $\checkmark$ & $\checkmark$ & & & & & & & & 3 \\
\hline & Tax benefits & & & & & & $\checkmark$ & $\checkmark$ & & & & & & $\checkmark$ & & & & & 3 \\
\hline & No subsequent investments & & $\checkmark$ & & & & & & & & & & & & & $\checkmark$ & & & 2 \\
\hline & High growth rate projection & & & & & & & & & & & & & & $\checkmark$ & & & & 1 \\
\hline \multirow[t]{6}{*}{ Management skills } & Managerial skills & $\checkmark$ & & $\checkmark$ & & & $\checkmark$ & $\checkmark$ & & $\checkmark$ & & & & & $\checkmark$ & & & & 6 \\
\hline & Marketing skills & $\checkmark$ & & & & & $\checkmark$ & $\checkmark$ & & $\checkmark$ & & & & & $\checkmark$ & & & & 5 \\
\hline & Financial skills & $\checkmark$ & & & & & $\checkmark$ & $\checkmark$ & & $\checkmark$ & & & & & & & & & 4 \\
\hline & Balanced team & & & & & & $\checkmark$ & $\checkmark$ & & & & & & & $\checkmark$ & $\checkmark$ & & $\checkmark$ & 5 \\
\hline & Technical skills & & & & & & $\checkmark$ & $\checkmark$ & & $\checkmark$ & & & & & & & & & 3 \\
\hline & Referral of entrepreneur & $\checkmark$ & & $\checkmark$ & & & & & & & & & & & & & & & 2 \\
\hline \multirow[t]{2}{*}{ Economic environment } & High variability in inflation & & & & & & & & & & & & & & $\checkmark$ & & & & 1 \\
\hline & GDP growth rate & & & & & & & & & & & & & & $\checkmark$ & & & & 1 \\
\hline \multirow{3}{*}{$\begin{array}{l}\text { Intuitional and regulatory } \\
\text { environment }\end{array}$} & Legal framework & & & & & & & & & & & & & & $\checkmark$ & & & & 1 \\
\hline & Favorable tax treatment & & & & & & & & & & & & & & $\checkmark$ & & & & 1 \\
\hline & Regulatory policies & & & & & & & & & & & & & & $\checkmark$ & & & & 1 \\
\hline
\end{tabular}

\section{Materials and methods}

\section{Identification of criteria for selecting startup businesses}

In this research, the criteria for selecting startup businesses of tech-focused government agencies were introduced by using mixed research methodologies. In the $1^{\text {st }}$ section, the qualitative research was based on the semi-structured interview method, including documentation analysis to understand the techfocused government agencies' decision-making mechanism for selecting startup businesses. The samples were selected by the purposive sampling method [30] with the following criteria. Firstly, the samples could provide insight into the decision-making of tech-focused government agencies. Secondly, they had experience supporting funds to tech startups for at least 1 year [31,32]. Thirdly, the government agency 
needed to provide funds to tech startups during the interview [31]. The profiles of the 7 tech-focused government agencies are listed in Table 2.

Table 2 Tech-focused government agency.

\begin{tabular}{ccc}
\hline $\begin{array}{c}\text { Tech-Focus } \\
\text { Government Agency }\end{array}$ & $\begin{array}{c}\text { Funds } \\
\text { (Million USD/Year) }\end{array}$ & Technology Focused \\
\hline TECHGOV1 & 6.07 & All technologies \\
TECHGOV2 & 1.65 & All technologies \\
TECHGOV3 & 3.36 & Digital technologies \\
TECHGOV4 & 9.24 & All technologies \\
TECHGOV5 & 0.12 & Technologies based on the investor's interesting \\
TECHGOV6 & 0.03 & Travel, service, industrial, agriculture, and food technologies \\
TECHGOV7 & 0.02 & Financial, investment, and insurance technologies \\
\hline
\end{tabular}

The interviews were conducted between September to October 2019 to understand the government agency's support and decision-making to select startup businesses. The semi-structured questionnaire comprised 3 parts: General information of funding programs for tech startups, the decision-making process of the government agency to select startup businesses, and finally, post activities supported by the backed tech startups. Subsequently, the transcriptions were collected, data reliability was verified by the interviewers for confirming the transcriptions' correctness. Data triangulation was used to increase the results' accuracy as the cross-validation of multiple data sources strengthened the findings. After exploring with the qualitative research, 3 new factors were discovered that influenced government agencies' decision-making as business potential, technology \& innovation, and personnel and teams.

This study adopted the quantitative research strategy based on a survey method for data collection in the next section. For the research tool, the questionnaire was developed based on 8 measurement items (Entrepreneur characteristics, product and services, market characteristics, financial consideration, business potential, technology \& innovation, personnel and teams, and management team) identified and modified after an extensive literature review and discovery by the qualitative research. Consequently, 71 items that belonged to the above 8 measurement items were included in the questionnaire. All variables were measured on a 5-Likert scale (From 1 - strongly disagree to 5 - strongly agree). The Likert scale is a rating scale for respondents to indicate their opinion on each question [30,32]. After developing the questionnaire, the researcher sent the questionnaire to 62 respondents (Decision-makers invited by the government agencies to select startup businesses). The participants feedbacked and returned the questionnaires, and 60 questionnaires were done entirely $(96.8 \%)$ and could be used to analyze in the next section for identifying criteria for selecting startup businesses.

\section{Principle component analysis}

Before principal component analysis (PCA), questions were verified using a reliability test with Cronbach's alpha method. If the Cronbach's alpha coefficient of any question were under the acceptable level $(\alpha=0.7)$, that question would not be used in PCA. We dimensionally reduce independent variables of this research by using PCA, which is used to compute principal components using the linear combination with the orthogonal transformation to explain information as much as possible [32,33]. The objectives of using PCA are as follows: 1) This method is used to solve the number of independent variables more than the sample size. For a condition of factor analysis, the sample size must be 6 to 10 times of independent variables [32]. 2) This method can reduce the number of variables without eliminating them for maintaining most of the information. 3) It can resolve multicollinearity by the extracted components has no relationship with other components. Besides, PCA creates a new group of components that the $1^{\text {st }}$ component has the highest level of variance and can explain the most information. The following components have their respective lower levels of variance. The categories of variables in this section were derived from previous research factors extracted using exploratory factor analysis [33]. The acquired components from using PCA are presented as shown in Table 3. 
Now, 12 extracted components by PCA are the appropriate main criteria used in selecting startup businesses by tech-focused government agencies. Fuzzy set theory converts the linguistic terms for each criterion rated by experts and decision-makers to triangular fuzzy numbers (TFN) for calculating the proposed framework in the next section.

\section{Fuzzy set theory}

Fuzzy set theory is a mathematical tool introduced by Zadeh to address uncertainty, subjectivity, vagueness, and imprecision in human judgments [34]. Currently, fuzzy set theory is widely used in MCDM approaches for useful applications in uncertain circumstances, and it is also efficiently applied for modeling human decisions and judgments $[7,16,34,35]$. After this, basic operations of fuzzy set theory are briefly presented.

\section{Definition 1: Fuzzy set}

A fuzzy set $\tilde{a}$ in the relative universe of $X$ is characterized by the membership function $\mu_{\tilde{a}}(x)$ that maps elements of $x$ in $X$ into real numbers in the range [0,1]. The membership function $\mu_{\tilde{a}}(x)$ is presented in the member of $x$ in $\tilde{a}$.

Table 3 Principal component analysis.

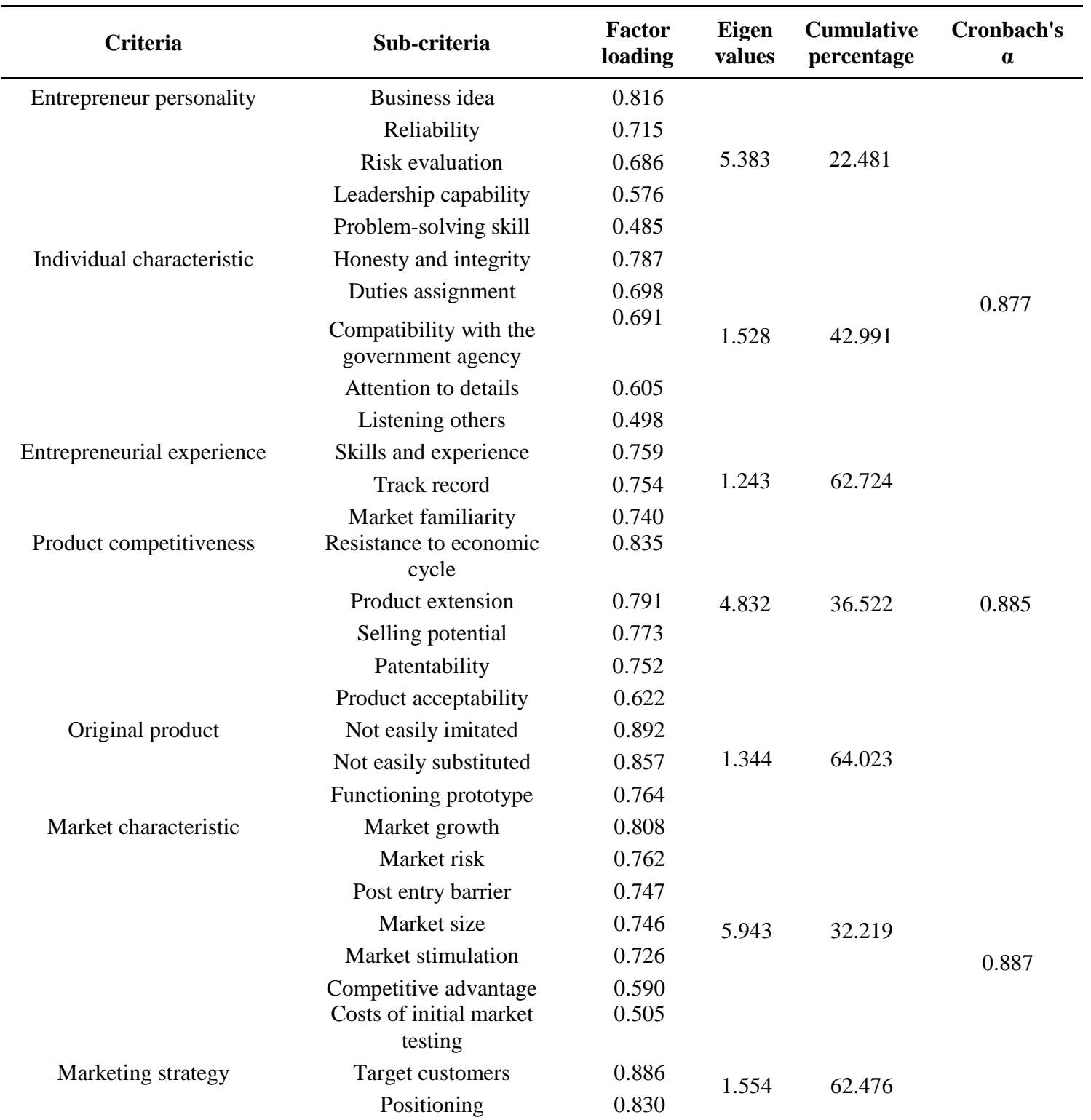




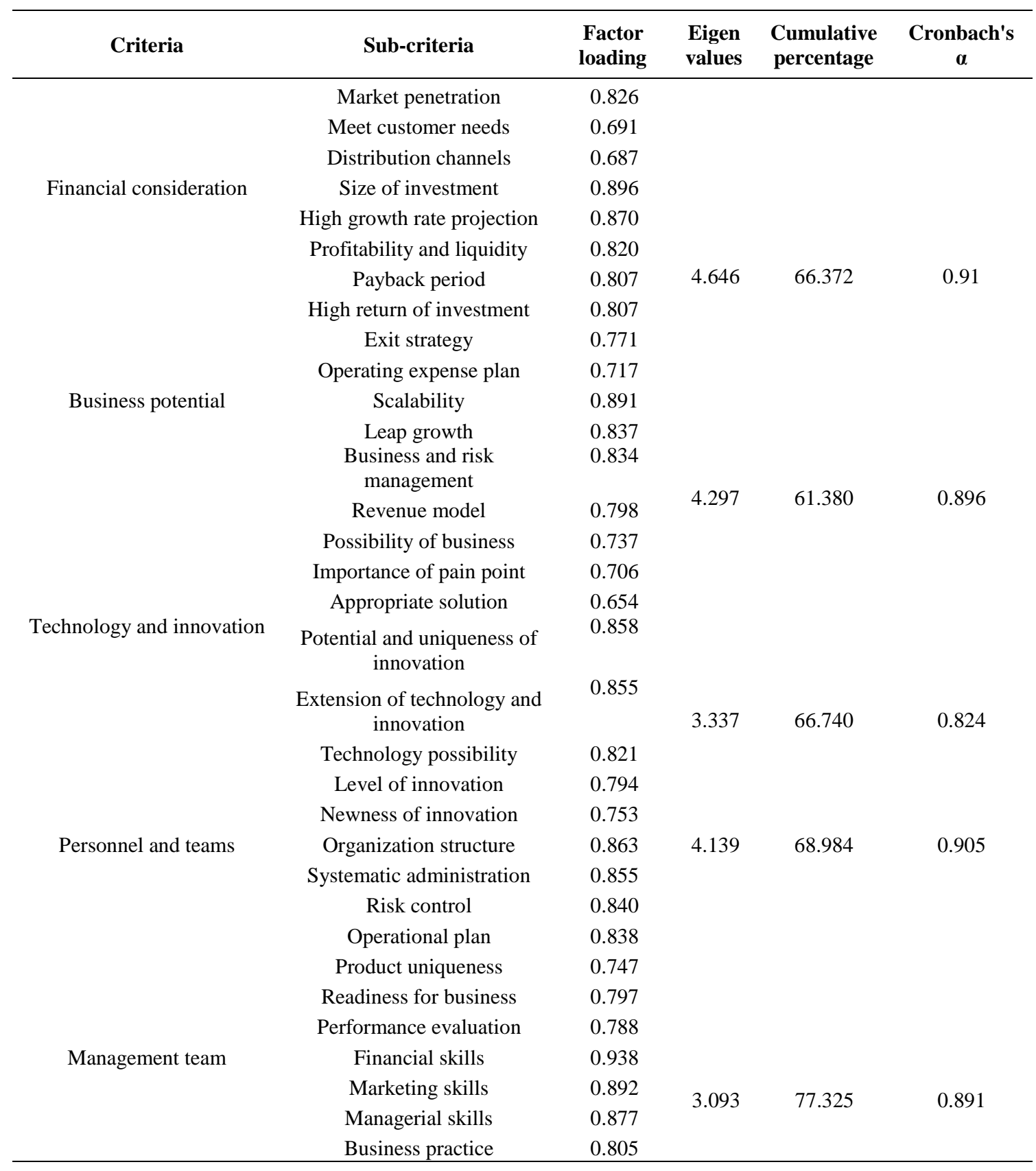

\section{Definition 2: TFN} (1).

A TFN is presented as $\tilde{a}=(a, b, c)$. The membership function $\mu_{\tilde{a}}(x)$ of TFNs $\tilde{a}$ are given in Eq.

$\mu_{\tilde{a}}(x)=\left\{\begin{array}{cc}\frac{x-a}{b-a} & \text { if } a \leq x \leq b \\ \frac{c-x}{c-b} & \text { if } b \leq x \leq c \\ 0 & \text { Otherwise }\end{array}\right.$

Where $a, b, c$ are real numbers and $a<b<c$. The value of $x$ at $b$ gives the maximal grade of $\mu_{\tilde{a}}(x)$, that is $\mu_{\tilde{a}}(x)=1$. The value of $x$ at $a$ gives the minimal grade of $\mu_{\tilde{a}}(x)$, i.e., $\mu_{\tilde{a}}(x)=0$. Constants $a$ and $c$ are the lower and upper bounds of the available area, respectively, and reflect the fuzziness of the considered data $[7,35,36]$. A TFN is represented as: 


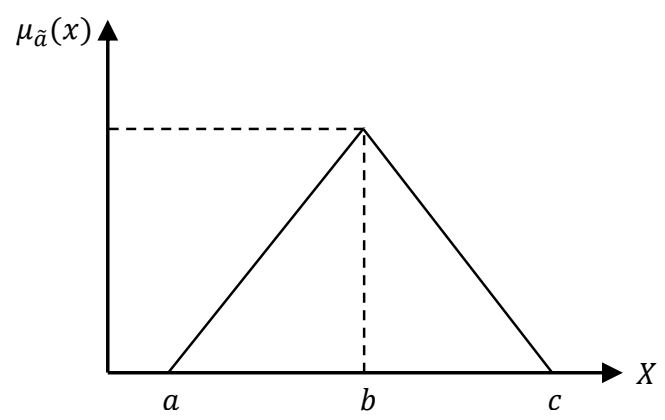

Figure 1 A TFN $\tilde{a}$.

\section{Definition 3: Arithmetic operations of TFNs}

Let $\tilde{a}=(a, b, c)$ and $\tilde{b}=\left(a^{\prime}, b^{\prime}, c^{\prime}\right)$ are 2 TFNs. Basic operations of 2 triangular numbers are presented as follows [27]:

$\tilde{a} \oplus \tilde{b}=(a, b, c)+\left(a^{\prime}, b^{\prime}, c^{\prime}\right)=\left(a+a^{\prime}, b+b^{\prime}, c+c^{\prime}\right)$

$\tilde{a}-\tilde{b}=(a, b, c)-\left(a^{\prime}, b^{\prime}, c^{\prime}\right)=\left(a-a^{\prime}, b-b^{\prime}, c-c^{\prime}\right)$

$\tilde{a} \times \tilde{b}=(a, b, c) \times\left(a^{\prime}, b^{\prime}, c^{\prime}\right)=\left(a a^{\prime}, b b^{\prime}, c c^{\prime}\right)$

$\tilde{a} \div \tilde{b}=(a, b, c) \div\left(a^{\prime}, b^{\prime}, c^{\prime}\right)=\left(\frac{a}{a^{\prime}}, \frac{b}{b^{\prime}}, \frac{c}{c^{\prime}}\right)$

\section{Definition 4: The distance between TFN}

Let $\tilde{a}=(a, b, c)$ and $\tilde{b}=\left(a^{\prime}, b^{\prime}, c^{\prime}\right)$ are 2 TFNs. Therefore, the distance between these 2 numbers is given as:

$d=\sqrt{\frac{1}{3}\left[\left(a-a^{\prime}\right)^{2}+\left(b-b^{\prime}\right)^{2}+\left(c-c^{\prime}\right)^{2}\right]}$

\section{Fuzzy TOPSIS for selecting startup businesses}

The TOPSIS is an MCDM approach that is popular and widely accepted by researchers, which Hwang and Yoon introduced in 1981 [34]. Fuzzy TOPSIS selects the alternative that is nearest to the fuzzy positive ideal solution (FPIS) and farthest the fuzzy negative ideal solution (FNIS). An FPIS consists of the best performance values of each alternative, while A FNIS consists of the worst performance values [34-36]. The fuzzy TOPSIS is used in various applications such as the investment in technological innovations [37], selection of instructors [35], or purchasing of smartphones [38].

In the next section, an outline with formulas and definitions of the fuzzy TOPSIS approach is culled from [7,35,36], is expressed and subsequently used for selecting startup business in tech-focused government agencies' perspective.

\section{Step 1: Determining linguistic variables}

In fuzzy set theory, linguistic scales transform linguistic terms into TFN for rating importance criteria and alternatives. The linguistic scales of Afful-Dadzie et al. are applied in this study as Table 4 [27]. Linguistic terms of 5 groups are Not feasible (NF), Feasible with changes (FC), Likely to be achieved (LA), Feasible (F), and Highly achievable (HA) to describe the potential of each startup business that is presented in the selection process of a tech-focused government agency. 
Table 4 Linguistic scale for the importance of criteria and ratings of alternatives.

\begin{tabular}{ccc}
\hline Linguistic terms & Fuzzy triangular numbers & Ratings of alternatives \\
\hline Very low $(\mathrm{VL})$ & $(0.0,0.1,0.3)$ & Not feasible (NF) \\
Low $(\mathrm{L})$ & $(0.1,0.3,0.5)$ & Feasible with changes (FC) \\
Medium $(\mathrm{M})$ & $(0.3,0.5,0.7)$ & Likely to be achieved (LA) \\
High $(\mathrm{H})$ & $(0.5,0.7,0.9)$ & Feasible (F) \\
Very high $(\mathrm{VH})$ & $(0.7,0.9,1.0)$ & Highly achievable (HA) \\
\hline
\end{tabular}

Step 1a: Determining weights of importance criteria

Next, decision-makers determine the critical levels or weights of each criterion as linguistic terms in Table 4. In Eq. (7), $w_{j}$ means the weight of criteria $C_{j}$ that is based on determining linguistic terms of decision-makers. Notice that $\widetilde{w}_{j}^{k}=\left(w_{j 1}^{k}, w_{j 2}^{k}, w_{j 3}^{k}\right)$ is presented in TFNs.

$\widetilde{W}=\left[\widetilde{w}_{1}, \widetilde{w}_{2}, \ldots, \widetilde{w}_{n}\right], j=1,2, \ldots, n$

Step 2a: Constructing fuzzy decision matrix

A situation in a selection process, where $m$ alternatives and $n$ criteria are presented to $k$ decisionmakers $\left(D_{1}, D_{2}, \ldots, D_{k}\right)$ for selecting the best alternative. Therefore, the MCDM problem in the context of fuzzy set theory can be expressed in a matrix format as follows:

$$
\begin{array}{cccccc}
C_{1} & C_{2} & \cdots & C_{n} & & \\
& A_{1} \\
A_{2} \\
\vdots \\
A_{m}
\end{array}\left[\begin{array}{ccccc}
\tilde{x}_{11} & \tilde{x}_{12} & \cdots & \tilde{x}_{1 n} \\
\tilde{x}_{21} & \tilde{x}_{22} & \cdots & \tilde{x}_{2 n} \\
\vdots & \vdots & \ddots & \vdots \\
\tilde{x}_{m 1} & \tilde{x}_{m 2} & \cdots & \tilde{x}_{m n}
\end{array}\right]
$$

Where $\tilde{x}_{i j}$ is the rating of alternatives with respect to criteria, are presented in TFNs.

Step 2b: Aggregating weights and ratings

In this step, the aggregation of fuzzy weights and ratings is presented using the interval value technique [27]. These can be defined as Eqs. (9) and (10), respectively.

$$
\begin{aligned}
& \widetilde{w}_{j}=\frac{1}{n}\left[\widetilde{w}_{j}^{1}+\widetilde{w}_{j}^{2}+\cdots+\widetilde{w}_{j}^{n}\right] \\
& \tilde{x}_{i j}=\frac{1}{n}\left[\tilde{x}_{i j}^{1}+\tilde{x}_{i j}^{2}+\cdots+\tilde{x}_{i j}^{n}\right]
\end{aligned}
$$

\section{Step 3: Normalized decision matrix}

This step normalizes the aggregated decision matrix obtained from the previous step. This normalization of the decision matrix is defined as:

$\tilde{R}=\left[\tilde{r}_{i j}\right]_{m \times n}, i=1,2, \ldots, m ; j=1,2, \ldots, n$

Where:

$$
\left.\begin{array}{c}
\tilde{r}_{i j}=\left(\frac{a_{i j}}{c_{j}^{*}}, \frac{b_{i j}}{c_{j}^{*}}, \frac{c_{i j}}{c_{j}^{*}}\right) \text { and } \\
c_{j}^{*}=\max _{j} c_{i j} \text { (Benefit criteria) }
\end{array}\right\}
$$


The normalization as above makes the fuzzy number in the range $[0,1]$.

\section{Step 4: Weighting normalized decision matrix}

The normalized fuzzy decision matrix is determined weights as the matrix $\tilde{V}$ that is computed with multiply by the weight $\widetilde{w}_{j}$ of each criterion and the fuzzy decision matrix that is normalized as $\tilde{r}_{i j}$. Therefore, it can present as the below equation.

$$
\left.\begin{array}{c}
\tilde{V}=\left[\tilde{v}_{i j}\right]_{m \times n}, \text { where: } \\
i=1,2, \ldots, m ; j=1,2, \ldots, n \\
\tilde{v}_{i j}=\tilde{r}_{i j}(.) \widetilde{w}_{j}=\left(a_{i j}^{\prime \prime}, b_{i j}^{\prime \prime}, c_{i j}^{\prime \prime}\right)
\end{array}\right\}
$$

\section{Step 5: Computing fuzzy positive and negative ideal solutions} and (16)

In this step, the computation of the FPIS $A^{*}$ and FNIS $A^{-}$of each alternative is defined as Eqs. (15)

$$
\left.\begin{array}{c}
A^{*}=\left(\tilde{v}_{1}^{*}, \tilde{v}_{2}^{*}, \ldots, \tilde{v}_{n}^{*}\right) \text { where: } \\
\tilde{v}_{j}^{*}=(c, c, c) \text { such that: } \\
\left.\begin{array}{c}
c=\max _{i}\left\{c_{i j}^{\prime \prime}\right\}, i=1,2, \ldots, m: j=1,2, \ldots, n
\end{array}\right\} \\
A^{-}=\left(\tilde{v}_{1}^{-}, \tilde{v}_{2}^{-}, \ldots, \tilde{v}_{n}^{-}\right) \text {where: } \\
\tilde{v}_{j}^{-}=(a, a, a) \text { such that: } \\
c=\min _{i}\left\{a_{i j}^{\prime \prime}\right\}, i=1,2, \ldots, m: j=1,2, \ldots, n
\end{array}\right\}
$$

\section{Step 6: Measuring distances from FPIS and FNIS}

Next, distances of $d_{i}^{*}$ and $d_{i}^{-}$of each weighted alternative from FPIS and FNIS are calculated as the below equation.

$d_{i}^{*}=\sum_{j=1}^{n} d_{v}\left(\tilde{v}_{i j}, \tilde{v}_{j}^{*}\right), i=1,2, \ldots, m$

$d_{i}^{-}=\sum_{j=1}^{n} d_{v}\left(\tilde{v}_{i j}, \tilde{v}_{j}^{-}\right), i=1,2, \ldots, m$

Where $d_{v}=(\tilde{a}, \tilde{b})$ is the measurement of the distance between 2 fuzzy numbers $\tilde{a}$ and $\tilde{b}$.

\section{Step 7: Computing closeness coefficient and ranking of alternatives} follows:

The close coefficient (CC) presents the distance between FPIS $A^{*}$ and FNIS $A^{-}$that is calculated as

$C C_{i}=\frac{d_{i}^{-}}{d_{i}^{-}+d_{i}^{*}}, i=1,2, \ldots, m$

The alternative with the highest closeness coefficient is determined as the best alternative, or it means that the alternative is nearest to FPIS and farthest FNIS.

\section{The process of selecting start-up businesses}

In this section, we design a decision-making framework for selecting startup businesses by techfocused government agencies. This proposed framework is based on the MCDM approach with the fuzzy TOPSIS technique, and appropriate selection criteria were identified. In the $1^{\text {st }}$ section, we reviewed relative literature works with selection criteria used by private equity investors $[6,33,39]$. The criteria gathered were carried out by the mixed research methodology, finally obtained appropriate criteria that were consistent with the decision-making of tech-focused government agencies. Next, external experts (no conflict of interest) determined weights of importance criteria by the Delphi method to achieve fairness, transparency, and elimination of bias in decision-making [39]. For the evaluation of tech startups, decision-makers rated startup businesses according to selection criteria. Then, the startup businesses' ratings were computed by the fuzzy TOPSIS approach to seeking the best and high potential 
startup business for funding tech-focused government agencies. The selection process of the startup business is presented in Figure 2.

\section{Results and discussion}

\section{Numerical example}

In this section, an example of a large tech-focused government agency in Thailand has been discussed to check the framework's performance in this article. This tech-focused government agency is a famous public financial resource for startups that are seeking initial funds. In 2019, the government agency provided funding over 30 million USD to support more than 80 startup businesses in several industries. For a funding program provided, hundreds of startups have submitted the program of the government agency for raising the funds and these startups have been considered as alternatives to the government agency. However, this is a key challenge for the government agency to select promising startups from hundreds of alternatives. Moreover, the government agency will have to abandon most of the startups that cannot perform as expected. Therefore, the selection of promising startups that are appropriate to be funded becomes difficult for them.

After preliminary screening of tech startups, the tech startups were categorized according to the technology groups that they used to develop their products and they would be evaluated by decisionmakers in each group. Generally, each technology group consisted of 7 - 10 startups for this evaluating stage [12]. The tech-focused government agency provided a data set of 10 tech startups that passed the preliminary selection, represented by $\mathrm{A}_{\mathrm{i}}(\mathrm{i}=1,2,3, \ldots, 10)$ respectively. Those tech startups were evaluated using 12 selection criteria of this study that were considered as benefit criteria, denoted as $\mathrm{C}_{\mathrm{i}}(\mathrm{i}$ $=1,2,3, \ldots, 12$ ) correspondingly. The government agency just informed us that 3 startups were funded and the rest of them failed. After testing the framework, the result of this framework will be confirmed with the government agency's result to check the framework's performance subsequently.

In determining weights of criteria, experts were purposively selected to determine weights of criteria neither involved in the selection process nor among the decision-makers. In this section, the survey form for determining weights of criteria was confidentially distributed to each expert. A middleman, who was not involved in the selection process, consolidated the forms backed by the experts. Additionally, the list of experts was undisclosed, so that experts could not know how each expert determined the weight of each criterion. This method could eliminate the issues of bias in decisionmaking [39].

In this article, the decision-making of tech-focused government agencies for selecting startup businesses is based on the proposed framework as shown in Figure 2, and its results are compared with the government agency's result to examine the efficiency of the proposed framework. Therefore, the numerical example is simulated as follows:

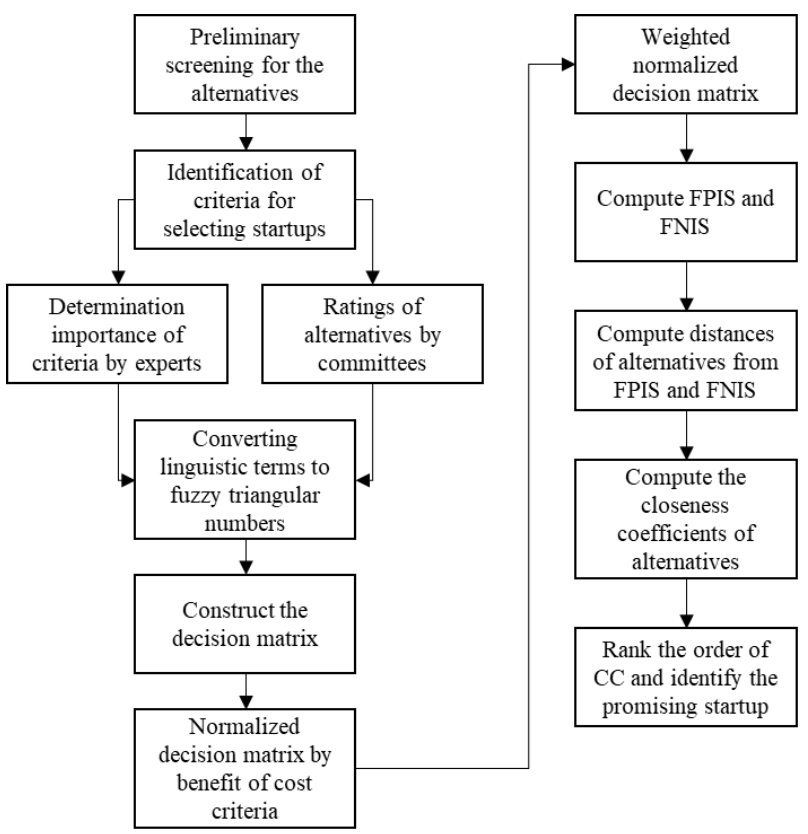

Figure 2 The procedure for tech-focused government agencies to select the promising tech startups. 
Step1: This step is involved with the determinations of linguistic variables, linguistic terms, alternatives, and decision-makers. Table 3 presents the acquired criteria from the PCA used as the selection criteria in the framework. As shown in Table 4, linguistic terms are used to determine the importance weights of each criterion and rating of alternatives.

Step 2: Experts rate to determine the importance weights of each criterion as shown in Table 4, and then the weights of experts are aggregated by Eq. (9) as shown in Table 5. In Table 5, it is shown that criteria 4 and 9 , the product competitiveness and business potential, are concluded the most important by the experts.

Table 5 Weighting importance criteria.

\begin{tabular}{ccccccc}
\hline & $\boldsymbol{E 1}$ & $\boldsymbol{E 2}$ & $\boldsymbol{E 3}$ & $\boldsymbol{E 4}$ & $\boldsymbol{E 5}$ & Aggregated weight \\
\hline$C 1$ & $\mathrm{VH}$ & $\mathrm{VH}$ & $\mathrm{M}$ & $\mathrm{M}$ & $\mathrm{H}$ & $(0.50,0.70,0.86)$ \\
$C 2$ & $\mathrm{H}$ & $\mathrm{VH}$ & $\mathrm{H}$ & $\mathrm{M}$ & $\mathrm{H}$ & $(0.50,0.70,0.88)$ \\
$C 3$ & $\mathrm{VH}$ & $\mathrm{M}$ & $\mathrm{H}$ & $\mathrm{H}$ & $\mathrm{VH}$ & $(0.54,0.74,0.90)$ \\
$C 4$ & $\mathrm{VH}$ & $\mathrm{VH}$ & $\mathrm{VH}$ & $\mathrm{H}$ & $\mathrm{VH}$ & $(0.66,0.86,0.98)$ \\
$C 5$ & $\mathrm{VH}$ & $\mathrm{M}$ & $\mathrm{L}$ & $\mathrm{M}$ & $\mathrm{H}$ & $(0.38,0.58,0.76)$ \\
$C 6$ & $\mathrm{H}$ & $\mathrm{VH}$ & $\mathrm{VH}$ & $\mathrm{M}$ & $\mathrm{H}$ & $(0.54,0.74,0.90)$ \\
$C 7$ & $\mathrm{VH}$ & $\mathrm{VH}$ & $\mathrm{H}$ & $\mathrm{M}$ & $\mathrm{VH}$ & $(0.58,0.78,0.92)$ \\
$C 8$ & $\mathrm{H}$ & $\mathrm{M}$ & $\mathrm{H}$ & $\mathrm{H}$ & $\mathrm{H}$ & $(0.46,0.66,0.86)$ \\
$C 9$ & $\mathrm{VH}$ & $\mathrm{VH}$ & $\mathrm{VH}$ & $\mathrm{H}$ & $\mathrm{VH}$ & $(0.66,0.86,0.98)$ \\
$C 10$ & $\mathrm{VH}$ & $\mathrm{VH}$ & $\mathrm{H}$ & $\mathrm{M}$ & $\mathrm{VH}$ & $(0.58,0.78,0.92)$ \\
$C 11$ & $\mathrm{H}$ & $\mathrm{VH}$ & $\mathrm{VH}$ & $\mathrm{H}$ & $\mathrm{H}$ & $(0.58,0.78,0.94)$ \\
$C 12$ & $\mathrm{VH}$ & $\mathrm{VH}$ & $\mathrm{VH}$ & $\mathrm{M}$ & $\mathrm{H}$ & $(0.58,0.78,0.92)$ \\
\hline
\end{tabular}

Step 3: The decision-maker rates each startup business according to selection criteria, and the decision matrix is constructed as Eq. (8). Subsequently, the ratings of alternatives by the decision-maker are aggregated as Eq. (10). The alternative rating of the decision-maker is presented in Table 6.

Step 4: For identifying benefit and cost criteria, all criteria are considered as a benefit. The aggregated decision matrix is normalized with the benefit criteria by Eqs. (11) and (12), as shown in Table 7.

Step 5: In this step, the normalized aggregated decision matrix is weighted using assigned weights to the criteria set as Eq. (14). The result is expressed in Table 8.

As acquired weighted normalized decision matrix, the FPIS and FNIS are defined as $\mathrm{A}^{*}$ and $\mathrm{A}^{-}$ respectively and computed as Eqs. (15) and (16). Therefore $\mathrm{A}^{*}$ and $\mathrm{A}^{-}$can be expressed as follows:

Table 6 Ratings of alternatives.

\begin{tabular}{ccccccccccc}
\hline & $A 1$ & $A 2$ & $A 3$ & $A 4$ & $A 5$ & $A 6$ & $A 7$ & $A 8$ & $A 9$ & $A 10$ \\
\hline$C 1$ & LA & F & F & F & LA & F & F & LA & LA & F \\
$C 2$ & F & F & LA & F & LA & HA & HA & LA & LA & F \\
$C 3$ & F & F & F & F & F & LA & LA & FC & FC & LA \\
$C 4$ & F & LA & F & F & LA & F & F & LA & LA & LA \\
$C 5$ & LA & F & HA & HA & F & F & LA & LA & LA & FC \\
$C 6$ & F & F & LA & LA & LA & LA & F & FC & FC & FC \\
$C 7$ & F & F & F & F & LA & LA & HA & FC & FC & NF \\
$C 8$ & F & LA & F & F & F & LA & HA & LA & LA & FC \\
$C 9$ & LA & FC & LA & LA & F & F & F & LA & LA & LA \\
$C 10$ & F & F & LA & F & LA & F & F & LA & LA & FC \\
$C 11$ & HA & LA & F & HA & F & F & LA & LA & FC & FC \\
$C 12$ & F & LA & LA & F & F & LA & F & LA & LA & FC \\
\hline
\end{tabular}

$\mathrm{A}^{*}=[(0.28,0.54,0.86),(0.35,0.63,0.88),(0.30,0.58,0.90),(0.37,0.67,0.98),(0.27,0.52,0.76),(0.30,0.58,0.90),(0.41,0.70$, $0.92),(0.32,0.59,0.86),(0.37,0.67,0.98),(0.32,0.61,0.92),(0.41,0.70,0.94),(0.32,0.61,0.92)]$

$\mathrm{A}^{-}=[(0.17,0.39,0.67),(0.15,0.35,0.62),(0.06,0.25,0.50),(0.22,0.48,0.76),(0.04,0.17,0.38),(0.06,0.25,0.50),(0.00,0.08$, $0.28),(0.05,0.20,0.43),(0.07,0.29,0.54),(0.06,0.26,0.51),(0.06,0.23,0.47),(0.06,0.26,0.51)]$. 
Step 6: The distances $d_{i}^{*}$ and $d_{i}^{-}$are calculated from each alternative to the fuzzy positive and negative ideal solutions by using Eqs. (17) and (18), respectively. The result is presented in Table 9. The closeness coefficient is calculated using Eq. (19), and its result provides the ranking order of alternatives as shown in Table 9. It identifies that alternative 7 (A7) is the best startup business, followed by A4, A1, A6, A3, A5, A2, A8, A9, and A10.

Table 7 Normalized decision matrix.

\begin{tabular}{|c|c|c|c|c|c|c|c|c|c|c|}
\hline & $A 1$ & $A 2$ & $A 3$ & $A 4$ & $A 5$ & $A 6$ & $A 7$ & $A 8$ & $A 9$ & $A 10$ \\
\hline $\mathrm{Cl}$ & $(0.33,0.56,0.78)$ & $(0.56,0.78,1.00)$ & $(0.56,0.78,1.00)$ & $(0.56,0.78,1.00)$ & $(0.33,0.56,0.78)$ & $(0.56,0.78,1.00)$ & $(0.56,0.78,1.00)$ & $(0.33,0.56,0.78)$ & $(0.33,0.56,0.78)$ & $(0.56,0.78,1)$ \\
\hline$C 2$ & $(0.50,0.70,0.90)$ & $(0.50,0.70,0.90)$ & $(0.30,0.50,0.70)$ & $(0.50,0.70,0.90)$ & $(0.30,0.50,0.70)$ & $(0.70,0.90,1.00)$ & $(0.70,0.90,1.00)$ & $(0.30,0.50,0.70)$ & $(0.30,0.50,0.70)$ & $(0.50,0.70,0.90)$ \\
\hline C3 & $(0.56,0.78,1.00)$ & $(0.56,0.78,1.00)$ & $(0.56,0.78,1.00)$ & $(0.56,0.78,1.00)$ & $(0.56,0.78,1.00)$ & $(0.33,0.56,0.78)$ & $(0.33,0.56,0.78)$ & $(0.11,0.33,0.56)$ & $(0.11,0.33,0.56)$ & $(0.33,0.56,0.78)$ \\
\hline C4 & $(0.56,0.78,1.00)$ & $(0.33,0.56,0.78)$ & $(0.56,0.78,1.00)$ & $(0.56,0.78,1.00)$ & $(0.33,0.56,0.78)$ & $(0.56,0.78,1.00)$ & $(0.56,0.78,1.00)$ & $(0.33,0.56,0.78)$ & $(0.33,0.56,0.78)$ & $(0.33,0.56,0.78)$ \\
\hline C5 & $(0.30,0.50,0.70)$ & $(0.50,0.70,0.90)$ & $(0.70,0.90,1.00)$ & $(0.70,0.90,1.00)$ & $(0.50,0.70,0.90)$ & $(0.50,0.70,0.90)$ & $(0.30,0.50,0.70)$ & $(0.30,0.50,0.70)$ & $(0.30,0.50,0.70)$ & $(0.10,0.30,0.50)$ \\
\hline C6 & $(0.56,0.78,1.00)$ & $(0.56,0.78,1.00)$ & $(0.33,0.56,0.78)$ & $(0.33,0.56,0.78)$ & $(0.33,0.56,0.78)$ & $(0.33,0.56,0.78)$ & $(0.56,0.78,1.00)$ & $(0.11,0.33,0.56)$ & $0.11,0.33,0.56)$ & $(0.11,0.33,0.56)$ \\
\hline C7 & $(0.50,0.70,0.90)$ & $(0.50,0.70,0.90)$ & $(0.50,0.70,0.90)$ & $(0.50,0.70,0.90)$ & $(0.30,0.50,0.70)$ & $(0.30,0.50,0.70)$ & $(0.70,0.90,1.00)$ & $(0.10,0.30,0.50)$ & $(0.10,0.30,0.50)$ & $(0.00,0.10,0.30)$ \\
\hline C8 & $(0.50,0.70,0.90)$ & $(0.30,0.50,0.70)$ & $(0.50,0.70,0.90)$ & $0.50,0.70,0.90)$ & $(0.50,0.70,0.90)$ & $(0.30,0.50,0.70)$ & $(0.70,0.90,1.00)$ & $(0.30,0.50,0.70)$ & $0.30,0.50,0.70)$ & $(0.10,0.30,0$ \\
\hline \multirow[t]{2}{*}{$C 9$} & $(0.33,0.56,0.78)$ & $(0.11,0.33,0.56)$ & $(0.33,0.56,0.78)$ & $(0.33,0.56,0.78)$ & $(0.56,0.78,1.00)$ & $(0.56,0.78,1.00)$ & $(0.56,0.78,1.00)$ & $(0.33,0.56,0.78)$ & $(0.33,0.56,0.78)$ & $(0.33,0.56,0.78)$ \\
\hline & $A I$ & $A 2$ & $A 3$ & A4 & A5 & A6 & $A 7$ & $A 8$ & A9 & $A 10$ \\
\hline $\mathrm{Cl}$ & $(0.17,0.39,0.67)$ & $(0.28,0.54,0.86)$ & $0.28,0$ & $(0.28,0.54,0.86)$ & $(0.17,0.39,0.67)$ & $(0.28,0.54,0.86)$ & $(0.28,0.54,0.86)$ & $(0.17,0.39,0.67)$ & $(0.17,0.39,0.67)$ & $(0.28,0.54,0.86)$ \\
\hline$C 2$ & $(0.25,0.49,0.79)$ & $(0.25,0.49,0.79)$ & $.15,0.35,0.62$ & $(0.25,0.49,0.79)$ & $(0.15,0.35,0.62)$ & $(0.35,0.63,0.88)$ & $(0.35,0.63,0.88)$ & $(0.15,0.35,0.62)$ & $(0.15,0.35,0.62)$ & $(0.25,0.49,0.79)$ \\
\hline$C 3$ & $(0.30,0.58,0.90)$ & $(0.30,0.58,0.90)$ & $(0.30,0.58,0.90)$ & $(0.30,0.58,0.90)$ & $(0.30,0.58,0.90)$ & $(0.18,0.41,0.70)$ & $(0.18,0.41,0.70)$ & $(0.06,0.25,0.50)$ & $(0.06,0.25,0.50)$ & $(0.18,0.41,0.70)$ \\
\hline C4 & $(0.37,0.67,0.98)$ & $(0.22,0.48,0.76)$ & $(0.37,0.67,0.98)$ & $(0.37,0.67,0.98)$ & $(0.22,0.48,0.76)$ & $(0.37,0.67,0.98)$ & $(0.37,0.67,0.98)$ & $(0.22,0.48,0.76)$ & $(0.22,0.48,0.76)$ & $(0.22,0.48,0.76)$ \\
\hline$C 5$ & $(0.11,0.29,0.53)$ & $(0.19,0.41,0.68)$ & $(0.27,0.52,0.76)$ & $(0.27,0.52,0.76)$ & $(0.19,0.41,0.68)$ & $(0.19,0.41,0.68)$ & $(0.11,0.29,0.53)$ & $(0.11,0.29,0.53)$ & $(0.11,0.29,0.53)$ & $(0.04,0.17,0.38)$ \\
\hline C6 & $(0.30,0.58,0.90)$ & $(0.30,0.58,0.90)$ & $(0.18,0.41,0.70)($ & $(0.18,0.41,0.70)$ & $(0.18,0.41,0.70)$ & $(0.18,0.41,0.70)$ & $(0.30,0.58,0.90)$ & $(0.06,0.25,0.50)$ & $(0.06,0.25,0.50)$ & $(0.06,0.25,0.50)$ \\
\hline$C 7$ & $(0.29,0.55,0.83)$ & $(0.29,0.55,0.83)$ & $(0.29,0.55,0.83)$ & $(0.29,0.55,0.83)$ & $(0.17,0.39,0.64)$ & $(0.17,0.39,0.64)$ & $(0.41,0.70,0.92)$ & $(0.06,0.23,0.46)$ & $(0.06,0.23,0.46)$ & $(0.00,0.08,0.28)$ \\
\hline$C 8$ & $(0.23,0.46,0.77)$ & $(0.14,0.33,0.60)$ & $(0.23,0.46,0.77)$ & $(0.23,0.46,0.77)$ & $(0.23,0.46,0.77)$ & $(0.14,0.33,0.60)$ & $(0.32,0.59,0.86)$ & $(0.14,0.33,0.60)$ & $(0.14,0.33,0.60)$ & $(0.05,0.20,0.43)$ \\
\hline C9 & $(0.22,0.48,0.76)$ & $(0.07,0.29,0.54)$ & $(0.22,0.48,0.76)$ & $(0.22,0.48,0.76)$ & $(0.37,0.67,0.98)$ & $(0.37,0.67,0.98)$ & $(0.37,0.67,0.98)$ & $(0.22,0.48,0.76)$ & $(0.22,0.48,0.76)$ & $(0.22,0.48,0.76)$ \\
\hline $\mathrm{ClO}$ & $(0.32,0.61,0.92)$ & $(0.32,0.61,0.92)$ & $(0.19,0.43,0.72)$ & $(0.32,0.61,0.92)$ & $(0.19,0.43,0.72)$ & $(0.32,0.61,0.92)$ & $(0.32,0.61,0.92)$ & $(0.19,0.43,0.72)$ & $(0.19,0.43,0.72)$ & $(0.06,0.26,0.51)$ \\
\hline C11 & $(0.41,0.7,0.94)$ & $(0.17,0.39,0.66)$ & $(0.29,0.55,0.85)$ & $(0.41,0.7,0.94)$ & $(0.29,0.55,0.85)$ & $(0.29,0.55,0.85)$ & $(0.17,0.39,0.66)$ & $(0.17,0.39,0.66)$ & $(0.06,0.23,0.47)$ & $(0.06,0.23,0.47)$ \\
\hline C12 & $(0.32,0.61,0.92)$ & $(0.19,0.43,0.72)$ & $(0.19,0.43,0.72)($ & $(0.32,0.61,0.92)$ & $(0.32,0.61,0.92)$ & $(0.19,0.43,0.72)$ & $(0.32,0.61,0.92)$ & $(0.19,0.43,0.72)$ & $(0.19,0.43,0.72)$ & $(0.06,0.26,0.51)$ \\
\hline
\end{tabular}

Table 9 Closeness coefficient and ranking of alternatives.

\begin{tabular}{ccccc}
\hline Alternative & $d^{*}$ & $d-$ & $C C i$ & Rank \\
\hline$A 1$ & 0.89 & 3.14 & 0.78 & 3 \\
$A 2$ & 1.58 & 2.45 & 0.61 & 7 \\
$A 3$ & 1.30 & 2.73 & 0.68 & 5 \\
$A 4$ & 0.69 & 3.33 & 0.83 & 2 \\
$A 5$ & 1.53 & 2.50 & 0.62 & 6 \\
$A 6$ & 1.23 & 2.80 & 0.69 & 4 \\
$A 7$ & 0.65 & 3.37 & 0.84 & 1 \\
$A 8$ & 2.94 & 1.09 & 0.27 & 8 \\
$A 9$ & 3.09 & 0.93 & 0.23 & 9 \\
$A 10$ & 3.37 & 0.65 & 0.16 & 10 \\
\hline
\end{tabular}

\section{Discussion}

Criteria in selecting venture capitalists were collected and analyzed by the exploratory factor analysis method, were introduced in 2016, and categorized into 7 main criteria [33], as shown in Table 1. After the interview with tech-focused government agencies, it was found that the government agencies did not consider the external factors as the economic environment and intuitional and regulatory environments in their selection process because the government agencies aimed to increase the number of start-businesses to stimulate the economy and assist backed tech startups to handle the government regulations. Furthermore, the government supports facilitated tech startups to surpass obstacles during the business operation. Therefore, the external factors inevitably conflicted with the objective of tech-focused government agencies. The quantitative research results had identified 3 additional factors (business potential, technology \& innovation, and personnel and teams) used by tech-focused government agencies, which were not found in the selection process of private equity investors. These factors focused on evaluating startup businesses in terms of the feasibilities of business, technology \& innovation, and teams that were currently considered as an essential part in driving technology businesses.

As the results of PCA, the main criteria of entrepreneur characteristics could be divided into 3 components as entrepreneur personality [6,40], individual characteristics [40], and entrepreneurship experiences [6,41]. The above components could support decision-makers to evaluate founders of startup 
businesses in more detail, and the components mentioned above were considered to success factors of SME and startup businesses [40,41]. Similarly, the main factor of products and services were extracted into product competitiveness $[11,33,41,42]$ and the original product $[41,42]$. Product competitiveness was used to evaluate the product capability to create revenue for the firm, while the original product was used to evaluate the unique product, not easily imitated, and replaced by competitors' products. Finally, the main factor of market characteristics could be extracted into market characteristics [6,33] and marketing strategy [41,42]. Market characteristics were used to consider the conditions, situations, and needs of the targeted market [6,33]. Simultaneously, the market strategy was used to considered strategies created by the firm in introducing its products or services to the target market and building the market acceptance of the target customers [41,42]. From the above results, emerging 3 components could be used to evaluate startup businesses more thoroughly and precisely.

Determining weights in this article was performed with the Delphi method by experts outside techfocused government agencies instead of assigning decision-makers to determine [28]. Normally, techfocused government agencies screened and selected qualified decision-makers for selecting startup businesses that possibly had a close relationship with the government officers to participate in the selection process [6,7]. This relationship would lead to unfairness and inequality in the selection process of the government agency. To address mentioned issues, the participation of a middleman to collect weights from outside experts was a practical approach and the list of outside experts was concealed so that no one knew how they determined weights according to selection criteria. Therefore, the above individuals were not involved with the selection process and the use of the Delphi method could build a fair, free of bias in decision-making, and transparent selection process for the decision-making of techfocused government agencies [39].

The results of the proposed framework had indicated that tech startups A7, A4, and A1 were the top 3 alternatives that should be funded by the tech-focused government agency. After getting the test result, the tech government agency confirmed the tech startups A7, A4, and A1 had been funded and shown higher performances than other startups during evaluation. However, the government agency additionally mentioned that 7 failed tech startups could develop their businesses further to mitigate weaknesses and return to raise funds in other funding programs. By comparison with the actual performance, the proposed framework was useful in decision-making by the government agencies for selecting startup businesses to acquire high potential or good performance tech startups to drive the national economy as the objectives of the government agencies.

\section{Conclusions}

SMEs such as tech startups are an important sector to generate income and employment in economic development. For supporting business operations in the private sector, tech-focused government agencies play an important role in supporting startup businesses by focusing on areas that tech startups are scarce and needed, such as capital, laboratory, resources, knowledge, and networks. With government supports provided, tech startups can confidentially operate their businesses and surpass obstacles. With the increase of tech startups since 2016, financial resources such as venture capitalists and angel investors are insufficient to meet tech startups' desires. Therefore, the government agencies have created several funding programs for tech startups that are frustrated in attracting venture capital investment. The funding of the government agencies can support these tech startups for transforming their business ideas into products and services and push them to create market acceptance successfully.

Even if government agencies have fully supported tech startups with essential activities and funding programs, the budgets are insufficiently allocated to support entire tech startups. With limited budgets, the government agencies need to meticulously screen submitted startup businesses in the funding programs to mainly acquire promising and high-potential tech startups for their funds. In selecting startup businesses, government agencies confront uncertain circumstances because decision-makers must evaluate startup businesses based on qualitative and quantitative selection criteria. Notably, the qualitative criteria lead to vagueness, uncertainty, subjectivity, and imprecision in human judgment. Therefore, the fuzzy set theory addresses the above issues to improve the government agency's decisions more accurately and efficiently. This article has introduced a decision-making framework based on the fuzzy TOPSIS approach to address uncertain circumstances. The proposed framework has consisted of selection criteria used for the government agency's decision that are identified by mixed research methodologies. Moreover, qualified experts determine the weights of criteria based on the Delphi method that influences the framework to create a fair and transparent selection process. Additionally, it can indicate the best performance or high potential startup business more efficiently. 
The practicality of the proposed approach is demonstrated using a numerical example based on the actual selection process of tech-focused government agencies. The proposed framework makes it feasible with the new additional important criteria such as business potential, technology \& innovation, and personnel and teams that support decision-makers to evaluate the businesses thoroughly. Experts and decision-makers are purposively selected as qualifications determined, and selected tech startups are in the same industry to avoid unfair advantages. The simulation results show that these tech startups' ranking orders correspond with the actual performance that is confirmed by the tech-focused government agency's result. From the comparison with the actual performance, the top 3 tech startups from the proposed model have high performances among these samples.

For this research, the limitation is tech-focused government agencies conceal the actual data of select startup businesses, which makes the proposed model is not comparable with the actual data in the government agencies' decision-making. However, the numerical example simulates the current selection process used by tech-focused government agencies to ensure the proposed model results are more reliable and valid.

\section{References}

[1] C Jones and P Pimdee. Innovative ideas: Thailand 4.0 and the fourth industrial revolution. Asian Int. J. Soc. Sci. 2017; 17, 4-35.

[2] P Klaasa, N Thawesaengskulthai and R Vaiyavuth. Factors to support a new tech start-up for business incubation. Asian J. Appl. Sci. 2019; 7, 320-7.

[3] Thailand Tech Startup Ecosystem, Available at: https://techsauce.co, accessed June 2020.

[4] Y Yang and Y Zhao. Modified PROMETHEEII for venture capital investment selection decisionmaking towards SMEs. J. Interdiscip. Math. 2018; 21, 1017-29.

[5] M Simic. Investment criteria set by venture capitalists. Ekon. Vjesn. 2015; 28, 457-79.

[6] E Afful-Dadzie and A Afful-Dadzie. A decision making model for selecting start-up businesses in a government venture capital scheme. Manag. Decis. 2016; 54, 714-34.

[7] E Afful-Dadzie, ZK Oplatkova and S Nabareseh. Selecting start-up businesses in a public venture capital financing using fuzzy PROMETHEE. Procedia Comput. Sci. 2015; 60, 63-72.

[8] J Kang, SH Gwon, S Kim and K Cho. Determinants of successful technology commercialization: Implication for Korean Government-sponsored SMEs. Asian J. Technol. Innov. 2013; 21, 72-85.

[9] SK Kim, BG Lee, BS Park and KS Oh. The effect of R\&D, technology commercialization capabilities and innovation performance. Technol. Econ. Dev. Econ. 2011; 17, 563-78.

[10] CR Ko and JI An. Success factors of student startups in Korea: From employment measures to market success. Asian J. Innov. Policy 2019; 8, 97-121.

[11] T Settajinda. Startup fundraising. 1 $^{\text {st }}$ ed. Boonsiri Printing, Bangkok, Thailand, 2019.

[12] A Taweesangrungroj, R Ratanabanchuen and S Sinthupinyo. Decision making process of Thai government agent for selection of technological startup companies in pitching of concept ideas. Asian J. Inf. Commun. 2019; 11, 25-38.

[13] X Tian, Z Xu, J Gu and E Herrera-Viedma. How to select a promising enterprise for venture capitalists with prospect theory under intuitionistic fuzzy circumstance? Appl. Soft Comput. 2018; 67, 756-63.

[14] KS Shin and SY Lee. Venture investment decision modeling using analytic hierarchy process. 2000.

[15] G Beim and M Levesque. Selecting projects for venture capital funding: A multiple criteria decision approach. In: Proceedings of the $17^{\text {th }}$ International Conference on Multiple Criteria Decision Making, Whistler, Canada. 2004, p. 1-23.

[16] Z Junjun and H Xiao. Study on the selection of venture capitalists based on fuzzy AHP. In: Proceedings of the $3^{\text {rd }}$ International Conference on Information Management, Innovation Management and Industrial Engineering, Kunming, China. 2010, p. 570-3.

[17] X Zhang. Venture capital investment selection decision-making base on fuzzy theory. Phys. Procedia 2012; 25, 1369-75.

[18] B Aouni, C Colapinto and DL Torre. A fuzzy goal programming model for venture capital investment decision making. Inf. Syst. Oper. Res. 2014; 52, 138-46.

[19] Annual Report 2019, Available at: https://www.nia.or.th, accessed January 2020.

[20] Digital Startup Fund, Available at: https://www.depa.or.th/th/, accessed January 2020.

[21] New Entrepreneur Creation, Available at: http://nec.dip.go.th/, accessed January 2020.

[22] IC MacMillan, L Zemann and P Subbanarasimha. Criteria distinguishing successful from unsuccessful ventures in the venture screening process. J. Bus. Ventur. 1987; 2, 123-37. 
[23] R Stuart and PA Abetti. Start-up ventures: Towards the prediction of initial success. J. Bus. Ventur. $1987 ; 2,215-30$.

[24] M Kakati. Success criteria in high-tech new ventures. Technovation 2003; 23, 447-57.

[25] S Chorev and AR Anderson. Success in Israeli high-tech start-ups; Critical factors and process. Technovation 2006; 26, 162-74.

[26] NMP Bocken. Sustainable venture capital - catalyst for sustainable start-up success? J. Clean. Prod. 2015; 108, 647-58.

[27] A Distanont. Criteria of venture capital for considering investment in start-ups in Thailand. In: Proceedings of the MakeLearn and TIIM International Conference: Integrated Economy and Society; Diversity, Creativity, and Technology, Naples, Italy. 2018, p. 289-94.

[28] K Maair and K Fangjai. The critical factors to success of startup business in Thailand. Payap Univ. J. 2018; 28, 143-58.

[29] RD Hisrich, MP Peters and DA Shepherd. Entrepreneurship. McGraw-Hill Education, New York, 2017.

[30] MS Saric. SMEs perspective on venture capital investment criteria - A study of Croatian SMEs. $J$. Contemp. Manag. Issues 2017; 22, 117-33.

[31] AL Zacharakis and GD Meyer. The potential of actuarial decision models: Can they improve the venture capital investment decision? J. Bus. Ventur. 2000; 15, 323-46.

[32] PD Leedy, JE Ormrod and LR Johnson. Practical research: Planning and design. Pearson Education, Essex, 2014.

[33] A Lertjanyakul. 2016, Venture capital evaluation criteria on startup in Thailand. Master Thesis. Thammasart University, Bangkok, Thailand.

[34] RK Yin. Case study research and applications: Design and methods. Sage publications, California, 2017.

[35] JS Petty and M Gruber. "In pursuit of the real deal": A longitudinal study of VC decision making. $J$. Bus. Ventur. 2011; 26, 172-88.

[36] M Dhochak and AK Sharma. Identification and prioritization of factors affecting venture capitalists' investment decision-making process: An analytical hierarchal process (AHP) approach. J. Small Bus. Enterp. Dev. 2016; 23, 964-83.

[37] R Bro and AK Smilde. Principal component analysis. Anal. Methods 2014; 6, 2812-31.

[38] S Wold, KH Esbensen and P Geladi. Principal component analysis. Chemom. Intell. Lab. Syst. $1987 ; 2,37-52$.

[39] K Vanichbancha. The statistic for research (in Thai). $10^{\text {th }}$ eds. Samlada Publishing, Bangkok, Thailand, 2016.

[40] C Hwang and K Yoon. Multiple attribute decision making. Springer-verlag, New York, 1981.

[41] R Rostamzadeh, K Ismail and EK Zavadskas. Multi criteria decision making for assisting business angels in investments. Technol. Econ. Dev. Econ. 2014; 20, 696-720.

[42] S Saghafian and SR Hejazi. Multi-criteria group decision making using a modified fuzzy TOPSIS procedure. In: Proceedings of the International Conference on Computational Intelligence for Modelling, Control and Automation and International Conference on Intelligent Agents, Web Technologies and Internet Commerce, Vienna, Austria. 2005, p. 215-21.

[43] B Sodhi and TV Prabhakar. A simplified description of fuzzy TOPSIS. ArXiv 2012. https://arxiv.org/abs/1205.5098

[44] A Suder and C Kahraman. Multicriteria analysis of technological innovation investments using fuzzy sets. Technol. Econ. Dev. Econ. 2016; 22, 235-53.

[45] NB Kore, K Ravi and SB Patil. A simplified description of fuzzy TOPSIS method for multi criteria decision making. Int. Res. J. Eng. Technol. 2017: 4, 2047-50.

[46] $\mathrm{J} \mathrm{Xu}, \mathrm{L} \mathrm{Yu}$ and $\mathrm{R}$ Gupta. Evaluating the performance of the government venture capital guiding fund using the intuitionistic fuzzy analytic hierarchy process. Sustainability 2020; 12, 6908.

[47] S Opasanon. Multiple criteria decision making for business and logistics management: Theory and application. Thammasart University, Bangkok, Thailand, 2016.

[48] A Kumbhat and Sushil. Ingredients of startup success. In: Proceedings of the $17^{\text {th }}$ Global Conference on Transforming Organizations through Flexible Management, Delhi, India. 2017, p. 119.

[49] MA Islam, MA Khan, AZM Obaidullah and MS Alam. Effect of entrepreneur and firm characteristics on the business success of small and medium enterprises (SMEs) in Bangladesh. Int. J. Bus. Manag. 2011, 6, 289-99. 
[50] J Hall and CW Hofer. Venture capitalists' decision criteria in new venture evaluation. J. Bus. Ventur. 1993; 8, 25-42.

[51] D Muzyka, S Birley and B Leleux. Trade-offs in the investment decisons of European venture capitalists. J. Bus. Ventur. 1996; 11, 273-87.

[52] T Chotigeat, I Pandey and DJ Kim. Venture capital investment evaluation in emerging markets. Multinatl. Bus. Rev. 1997; 5, 54-62.

[53] I Pandey, J Gupta and R Wickramatilke. Venture capital investment process and evaluation in a developing country: A study of Thailand. J. Appl. Financ. 1995; 1, 90-111.

[54] C Mason and M Stark. What do investors look for in a business plan? A comparison of the investment criteria of bankers, venture capitalists and business angels. Int. Small Bus. J. 2004; 22, 227-48. 